\title{
O conceito de imaginação e sua vinculação ao conceito de religião na obra de Rubem Alves
}

\author{
Fabiano Veliq*
}

\begin{abstract}
Resumo
O debate sobre a religião é algo que permeia a história da filosofia e é tratado por muitos filósofos sob diferentes aspectos. No entanto, percebe-se que vários deles vinculam a religião a algo completamente humano. Apenas o ser humano faz religião. E é a partir desse pressuposto que Rubem Alves partirá para formular o seu conceito de religião. Para isso, fará uso do conceito de imaginação para mostrar como é que a religião se vincula de forma íntima a tal conceito.

Neste artigo, pretende-se evidenciar o conceito de imaginação na obra de Rubem Alves e mostrar como esse conceito é crucial na construção do seu entendimento de religião.

Palavras chaves: Religião. Imaginação. Homem. Utopia.

\section{The concept of imagination and its link to the concept of religion in the work of Rubem Alves}

\begin{abstract}
The debate about religion is something that permeates the history of philosophy and many philosophers had been treated this theme through many differents aspects. However, we can notice that many of them bind the religion to something completely human. Only the human being does religion. And it is from this assumption that Rubem Alves will start to formulate his conception of religion. For this matter, he will make use of the conception of imagination to show how religion is linked intimately to the concept.

In this article, we intend to highlight the concept of imagination in the work of Rubem Alves and show how such a concept is crucial in building their concept of religion.
\end{abstract}

Key-words: Religion. Imagination. Man. Utopia.

* UFMG. Graduado em Filosofia pela UFMG, Especialista em Teologia Sistemática pela Faculdade Batista de Belo Horizonte, Mestre em Filosofia da Religião pela FAJE, Doutor em Psicologia pela PUC Minas. Terminou o estágio pós-doutoral na PUC Minasem Psicanálise.veliqs@gmail.com 


\section{Introdução}

Rubem Alves foi um teólogo e filósofo brasileiro que produziu uma vasta obra sobre diversas áreas do saber. Um dos temas a respeito dos quais se debruçou durante boa parte de sua vida foi a religião. Alves construirá seu conceito de religião a partir do conceito de imaginação. Tal temática é abordada por Alves de forma mais sistemática em seus escritos mais antigos, e de maneira mais "solta" em seus escritos mais recentes. Por esse motivo, priorizamos neste trabalho o uso de textos em que a temática da imaginação como modificadora do mundo se apresenta de forma mais sistemática, como A gestação do futuro, $O$ suspiro dos oprimidos, $O$ que é religião, $O$ enigma da religião. Daí, nossa ênfase nos mesmos, como se notará no decorrer deste artigo. Nesse sentido, justifica-se a ausência de outros textos de Alves, como Dogmatismo e Tolerância, Protestantismo e Repressão, Da esperança e outros, uma vez que nesses livros a temática da imaginação não aparece de forma sistemática, embora desponte como fio condutor para o desenvolvimento de algumas ideias do autor em questão.

Podemos perceber claramente a presença de dois grandes autores na elaboração do conceito de religião proposto por Rubem Alves. O primeiro deles é Marx e, posteriormente, Freud.

Como poderá ser notado, há uma presença do pensamento de Marx na elaboração desse texto, mas ela se encontra mais resumida e isto se deve ao fato de que a apropriação por Alves dos conceitos marxistas se dará mais na elaboração de sua teologia do que na sua filosofia da religião. Para se apropriar dos conceitos marxistas, Alves usará outro teólogo importante, Bonhoeffer e, a partir da interpretação bonhoefferiana, lidará com os conceitos marxistas. Isso culminará no que depois ficou conhecido como teologia da libertação. Se fôssemos nos concentrar nessa parte do pensamento alvesiano, correríamos o enorme risco de fugir da proposta do presente artigo. Há sim um pressuposto marxista no pensamento alvesiano, mas este se deslocará para um viés teológico e só fará sentido dentro de um escopo que tentará mostrar a relação entre a ressurreição do Cristo como manifestação histórica da divindade e a coerência do deus de Israel, que sempre se constituiu como agente na história do homem. Tal temática será abordada por ele em sua dissertação de mestrado de 1963, e também na tese de doutorado de 1969. Desse modo, se abordássemos aqui em detalhe a apropriação de Marx por Rubem Alves, teríamos de recorrer a vários pressupostos teológicos que se desviariam do foco deste trabalho. Pode-se notar que, nas obras específicas sobre filosofia da religião, a alusão ao pensamento de Marx se dá de forma muito reduzida e 
apenas fazendo alusão a textos e artigos mais antigos, nos quais a presença de Marx se faz de modo mais marcante. Justifica-se, portanto, a pouca ênfase em Marx neste artigo e por isso o leitor perceberá uma presença mais marcante do pensamento freudiano.

\section{O Conceito de imaginação em Rubem Alves}

O homem, como ser de desejo e ser social, procura transformar o mundo de forma que este seja expressão do próprio corpo do homem. Com efeito, para Alves, o corpo tem uma prioridade axiológica sobre tudo, pois consiste no fundamento e na meta do mundo humano. O corpo em Alves é o ponto de partida de sua reflexão. O sujeito é corporal e toda a sua relação com o mundo se dá por meio do corpo. Alves propõe voltar o olhar para o corpo para que entendamos que ele é a origem de toda ação e valorização, a sobrevivência dele é o mais importante, e por isso toda e qualquer ação tem que colocá-lo sempre no centro, sempre como fim, nunca um meio para algo. Segundo Alves:

No princípio era o corpo [...] Tudo quanto o homem criou - seus instrumentos de trabalho, sua sociedade, seus valores, suas aspirações, suas esperanças, seus mitos, sua linguagem, sua religião, suas ideologias, sua ciência e qualquer outra coisa que se possa inventariar como surgida do homem - ficou engendrado em meio a sua luta pela sobrevivência. Todos os seus descobrimentos foram criados pelo corpo, em seu próprio benefício. [...] O corpo contém em si, deste modo, uma prioridade axiológica sobre todas as outras coisas porque é o fundamento e o fim do mundo humano (ALVES, 1975, p. 182, 183).

A imaginação é função do corpo, é por meio dela que o homem é capaz de se estender para além de sua carne e tentar construir um mundo que seja expressão sua. É nesse ponto que, para Alves, a imaginação terá um papel fundamental, pois é ela que declara o absurdo da realidade face ao desejo humano.

O conceito de imaginação é de extrema importância para se entender o pensamento alvesiano. Esse conceito perpassa toda sua obra e é de incrível alcance para a compreensão do tema da religião em sua produção.

Alves afirma que a relação do homem com a natureza é diferente da que os animais mantêm com ela. Enquanto esses apenas se adaptam à natureza, o ser humano está em constante luta contra ela. O homem não se adapta, mas tenta humanizar a natureza. Dessa tentativa de humanização surge a cultura. A cultura é, portanto, uma tentativa de humanização da natureza. 
No entanto, à medida que o tempo decorre, a cultura, como criação do homem, parece adquirir um status próprio: aquilo que era criação do homem passa a assumir o papel criador, e o homem, que antes era o criador da sociedade, passa a ser apenas mais uma peça para o funcionamento dela. De criador, o homem se transforma em criatura da sociedade, passa a ser mera peça para o funcionamento do sistema. O homem é transformado em algo que deve "funcionar" para a sociedade.

O homem transformado em função reprime os desejos do seu corpo e passa a agir de acordo com os desejos do sistema. Esse sistema que subjuga o corpo não pode continuar indefinidamente, pois o corpo deve ser considerado como fim e não como meio. Alves propõe um retorno ao corpo, já que a personalidade do homem mostra que este não é igual aos animais. Ele não se ajusta à natureza, mas busca um significado para além dela, pois quer viver em um mundo que faça sentido, onde os valores humanos sejam incorporados à existência. Nesse sentido, o ser humano transcende a natureza e o determinismo biológico de mero ajustamento, que caracteriza os animais.

A luta do homem é primeiramente pela sobrevivência, mas ele ultrapassa esse nível ao buscar por um sentido. É nessa busca de sentido que nasce a cultura. A cultura é um ato humano de criação que não é determinado pela estrutura biológica, mas é evidenciado pela "incompletude" do homem. Logo, essa criação é realizada primeiramente por necessidade do corpo, mas o homem não vive só de pão. Como ser inacabado, ser de desejo, como já apontava Freud, a quem Alves segue nesse ponto, o homem cria a cultura como extensão de seu corpo na busca de sentido.

O homem não está determinado por seu passado, mas o usa como forma de construir o novo, um futuro aberto. Ele não é determinado pela sua estrutura biológica, pois possui o poder de se superar, de criar coisas. É isso que Alves chama de imaginação, esse deixar para trás o passado que se mostrou disfuncional e opressivo e esse agir inspirado pelas intenções. Tudo isso é realizado através de uma ação do corpo.

A imaginação é, portanto, a chave para entender a relação do homem para com o mundo, ela é aquela que faz do homem um ser modificador da natureza. E esse poder transformador se dá por meio da linguagem, uma vez que essa é também um ato criativo do homem.

Para Alves, assim como vemos com os nossos olhos, mas não os vemos, assim também acontece com a realidade. Há nela vários "acordos silenciosos" 
que funcionam como nossos olhos. Só vemos o mundo por meio desses acordos que não vemos, acordos esses que são cristalizados pela ciência.

Segundo o autor, a ciência pressupõe que conhecer é reduplicar. A objetividade da ciência acaba por considerar que a realidade está toda ela pronta e que o conhecimento nada mais é que uma cópia do real. Se realmente é assim, a pessoa, para ser considerada normal, deve ajustar-se à regra do copiar. Esse ponto já foi elucidado por Freud, quando ele afirma que o neurótico dá um valor excessivo aos seus desejos e se recusa a aceitar a realidade. A pessoa normal é a que se ajusta ao sistema. ${ }^{1}$

Alves procura mostrar outro pressuposto da mentalidade científica que é o fato de que "o mundo já está dado". As forças que movem a História são independentes do homem. Este pode até transformar o mundo, mas até certo ponto e sem romper o sistema vigente. Afinal, ele seria apenas um "joguete" dentro de um sistema que lhe é alheio, uma vez que a História independe de suas ações, cabe a ele apenas o "descobrir" a realidade dada. Assim, sua ação não brota da sua liberdade, mas de um predeterminismo, seja ele biológico, divino ou social. Nessas condições, não resta lugar algum para a imaginação. Se o conhecimento é reduplicação, a imaginação deve ser banida como loucura, falsa consciência e enfermidade.

Alves se atém bastante ao último ponto, pois para ele "Religião é imaginação, e inversamente, a imaginação tem sempre uma função religiosa, para o homem" (ALVES, 2007, p. 24). Por meio da religião, pode-se ver as coisas reais sob o esplendor mágico da imaginação.

Segundo Alves, ao aceitar a religião e a imaginação como enfermidade, estamos concordando com os "acordos silenciosos" que controlam a mentalidade científica, de acordo com os quais a consciência nada mais é que uma máquina reduplicadora. A criação do novo é impossível.

No entanto, o homem não lida com o mundo de forma direta, e sim de modo emocional, pois seu contato com ele se dá sob o imperativo da sobrevivência. E uma vez que o homem quer viver, a natureza nunca aparece como fria e sem sentido, ela tem um significado: o ambiente promete vida ou morte

Sobre esse tema em Freud confira Freud, Sigmund. Formulações sobre os dois princípios do funcionamento mental. Editora IMAGO. Rio de Janeiro, RJ. Obras Psicológicas Completas de Sigmund Freud 1976, p. 279.

Volume 12.4 Freud, Sigmund. O mal-estar da civilização. Editora IMAGO. Rio de Janeiro, RJ. Obras Psicológicas Completas de Sigmund Freud, 1976, v. 21, p. 94. 
ao homem, prazer ou dor. A experiência imediata da natureza é, portanto, emocional e, por conseguinte, constitui a matriz emocional que estrutura o mundo em que vivemos. A consciência do mundo surge das experiências decorrentes da tentativa de sobreviver no mundo, e como o corpo é o que luta para sobreviver diante da natureza, a consciência, se faz, portanto, função do corpo. Alves afirma que, se o cerne da consciência é emoção e valor, então a consciência é radicalmente religiosa. Alves atesta isso quando considera que o conhecimento não é uma cópia, mas uma organização do real. O real, portanto, só se torna humano depois de receber um significado pelo homem, depois que o último confere seus valores ao mundo.

Colocar a imaginação sob a suspeita de loucura é aceitar o pressuposto de que só é válido o conhecimento que se paute pela lógica da relação sujeito-objeto. A vida, no entanto, está antes disso. A vida é relação, e por ser dessa forma, a religião não utiliza sinais, mas símbolos. Do mesmo modo que os sonhos não podem ser entendidos a partir da relação sujeito-objeto, também a religião e a imaginação não podem ser compreendidas dessa forma. Sonhos são expressos em forma de símbolo. No signo, uma palavra remete a um objeto, ao passo que nos símbolos isso não ocorre. A relação não é direta. O símbolo remete a algo além do objeto, revelando e escondendo ao mesmo tempo.

A partir disso, Alves afirma que "a religião é para sociedade aquilo que o sonho é para o indivíduo. A religião revela a lógica do coração, a dinâmica do "princípio de prazer", na medida em que ele luta por transformar um caos não humano ao seu redor em uma ordo Amoris. ${ }^{2}$

A imaginação é uma luta do homem contra o realismo advindo da visão cientificista do mundo moderno. Ela se constitui como um novo paradigma de compreensão do homem e, por conseguinte, de compreensão do mundo como manifestação do humano.

A partir de tal definição, Alves mostrará que a imaginação se constitui como novo paradigma para se tentar entender o homem. Ele faz uso da

\footnotetext{
2 Alves, Rubem. O enigma da religião, 2007, p. 27. (Em A gestação do futuro, p. 87, lemos: "A imaginação é para a sociedade o que os sonhos são para os indivíduos".) Nota-se aqui uma interessante aproximação entre religião e imaginação, de forma que isso dá a religião o caráter transformador da sociedade que Alves tentará mostrar em vários momentos de suas obras. Assim como a imaginação, i.e., os desejos do homem de viver em um mundo com sentido, ela teria esse mesmo caráter e por isso ela não deve ser rejeitada, mas sim entendida sob esse aspecto renovador. É a partir dessa visão que Alves desenvolverá a Teologia da Libertação no final dos anos de 1960.
} 
teoria de Thomas Kuhn, e afirma que o paradigma científico não funciona na explicação do mundo. Observar a realidade sob a ótica da superação por meio da ciência não gerou o fim desejado.

Assim como acontece na ciência, seguindo a sugestão de Kuhn, um novo paradigma só é adotado quando o antigo não mais resolve os problemas novos. Voltando os olhos para a História, nota-se que um dos primeiros paradigmas adotados foi o da explicação mitológica do mundo. A última foi superada com o advento da ciência, que pretendeu solucionar problemas que a mitologia não mais conseguia resolver. No entanto, os inúmeros problemas surgidos com o progresso da ciência, haja vista as duas grandes guerras mundiais, as diversas doenças advindas com o progresso científico e a falta de resolução das questões essenciais do homem, fizeram que o ideal positivista do homem científico caísse em descrédito. A sociedade que mais se desenvolvia cientificamente se viu envolta em problemas que a ciência não conseguia resolver. Tudo isso fez que o paradigma científico entrasse em crise também. É preciso, portanto, um novo paradigma. Segundo Alves, "quando a imaginação modular já exauriu as suas possibilidades chegou o tempo da imaginação criativa" (ALVES, 1987, p. 78).

Para o autor, nessa dinâmica algo tem de morrer para que haja um novo nascimento. O processo é descontínuo, envolvendo morte e ressurreição. A crise do paradigma clama por um novo, pelo abandono do velho e por um novo começo. Para Rugg, essa é a essência do ato criativo: "A chave da natureza do ato criativo consiste em abandonar pressuposições há muito mantidas e recomeçar a partir de uma nova orientação" (RUGG apud ALVES, 1987, p. 75).

No entanto, pelos pressupostos da ciência, o ato criativo é proibido. Conhecimento é reduplicação. Por isso, o ato criativo geralmente ocorre na clandestinidade. Por ser clandestino, será tido como enfermidade. Se ser normal é ser funcional, é estar ajustado ao sistema, o ato criativo será, portanto, um grito de revolta contra a realidade.

Conforme mencionado, a antropologia ancorada na visão científica do mundo afirma que o homem é apenas uma função da estrutura social. No entanto, é preciso lembrar que a estrutura social é criação do homem e não o contrário, como evidenciado por Marx. Não é o homem quem deve ser julgado pelo sistema, mas o sistema pelo homem. Segundo Alves, "A imaginação não pode ser declarada desequilibrada por não concordar com os fatos da realidade. É a realidade que deve ser declarada louca quando não concorda com as aspirações da imaginação" (ALVES, 1987, p. 83). 
Para Alves, tal visão cientificista do mundo subverte a ordem das coisas e esquece que o mundo humano é o resultado de atos criativos e não há ato criativo sem imaginação. Esta se coloca, portanto, como novo paradigma, uma vez que ela é pré-requisito do ato criativo, é o ato criativo na mais alta expressão da vida humana.

\section{As três "intenções" da imaginação}

Analisando então esse ato criativo, Alves afirma que a imaginação possui três "intenções": uma intenção mágica, uma intenção lúdica e uma intenção utópica.

Sobre a primeira, o autor diz que há uma igualdade entre magia e imaginação. Para ele, "a magia é ideal para os nossos propósitos, assim como a interpretação dos sonhos é crucial para a psicanálise. A magia é a imaginação apoderando-se do corpo, e a imaginação uma forma secreta de magia" (ALVES, 1987, p. 86). Dessa forma, se a magia for considerada como disfuncional e irracional, assim também a imaginação o será.

Freud também percebeu a relação entre magia e imaginação. Como já descrito, o neurótico, para Freud, é aquele que não aceita o veredicto do princípio de realidade e, por isso, constrói um mundo em que seu desejo é o regente. Como afirma Freud, "O neurótico cria em seus sintomas satisfações substitutivas para si, e estas ou lhe causam sofrimento em si próprias, ou se lhe tornam fontes de sofrimento pela criação de dificuldades em seus relacionamentos com o meio ambiente e a sociedade a que pertence" (FREUD, 1930/1976 p. 58, 59).

Alves afirma que, ao fazer isso, o neurótico assemelha-se ao mágico. Assim como o neurótico cria outra realidade pautada no desejo a partir da força do pensamento, ou melhor, pensando seus desejos, assim também age o mágico, como se a realidade pudesse ser modificada por meio da consciência. Da mesma forma que o neurótico, ele acredita na "onipotência do desejo". De acordo com essa interpretação, o mágico seria alguém que crê que o mundo pode ser criado pelo poder da palavra.

Como os sonhos têm suas raízes na situação existencial do homem, na sua relação com o mundo que o rodeia, para entendê-los é preciso compreender as condições de vida que os fazem nascer. E, segundo Alves, "A imaginação é para a sociedade o que os sonhos são para os indivíduos. Em toda utopia, trabalho artístico, fantasia religiosa e ritual mágico, a sociedade fala de seus sentimentos ocultos" (ALVES, 1987, p. 87). Conclui-se assim 
que, na magia, o homem ainda acredita na modificação da realidade pelo pensamento, pela palavra, e como essa é também uma forma de imaginação, a última é em si mesma mágica.

A magia não é, portanto, uma forma primitiva de se manter uma relação com o mundo, mas evidencia o desejo do homem de transformá-lo num lugar onde seja possível amar. Malinkowski, segundo Alves, entende que a magia surge quando o homem se vê impotente frente à realidade que o cerca. ${ }^{3}$ Quando o homem sente-se seguro diante de determinada situação, não há a necessidade da magia, ele é senhor daquele lugar e, portanto, ele pode confiar na força do seu braço. No entanto, quando uma situação revela que os recursos de que ele dispõe não são suficientes para lidar com ela, o homem recorre à magia. A magia, portanto, surge quando o homem sente-se impotente para levar a cabo sua intenção

por meio de seus próprios recursos. Esse ponto evidencia uma oposição a Freud. A magia não se origina na onipotência do desejo, mas sim na percepção da impotência.

Ao tentar impor seu desejo à realidade, que é mais forte do que ele e sempre sai vitoriosa, o homem apela à magia, a qual se torna então uma forma de revolta contra a realidade estabelecida. Essa revolta é pautada no desejo humano de transformar o mundo em um lugar que seja extensão do próprio corpo. A magia acaba sendo assim uma expressão da esperança, pois permite ao homem acreditar que o presente pode ser transformado. $O$ ser humano atua pela paixão por algo ausente, e por isso se recusa a aceitar o presente:

Intentamos dar à luz a esperança, fazê-la encarnar-se; intentamos transformar o ausente no presente. É-se literalmente possuído pela esperança. Se recordarmos que a ação humana consiste essencialmente numa busca de valores, perceberemos então que por detrás do ato criador da cultura e por detrás da magia opera uma mesma e única dinâmica (ALVES, 1987, p. 90).

Naqueles pontos em que a realidade impede que o homem crie o objeto do seu desejo pela força de sua mão, ele preserva sua aspiração por meio da ação simbólica. A intenção da magia, portanto, não é descrever como o mundo é, mas sim como o mundo deveria ser de acordo com as exigências da personalidade. "A magia é uma expressão dos sentimentos, intenções e

\footnotetext{
Cf. Malinowski, Bronislaw. Magic, science or religion, 1948, p. 79.
} 
esperanças, que constituem os fundamentos de tudo o que o homem faz" (ALVES, 1987, p. 91).

A magia então não é uma neurose que será superada, como queria Freud, mas sim uma manifestação da intenção básica da personalidade, a saber, criar um mundo que possa ser amado. E o homem age assim porque ele quer viver em um mundo que faça sentido. Um mundo que negue as aspirações do homem é um mundo insano que deve ser abolido. Logo, a magia, como evidência do ato criativo, não deve ser considerada absurda, mas o mundo que a impede é que deve ser considerado absurdo.

O pensamento mágico envolve uma percepção da impotência frente a uma realidade que nega o desejo e uma declaração da prioridade axiológica do desejo sobre essa mesma realidade. Isso faz que a magia tenha um caráter ético, já que visa àquilo que deve ser. A realidade “deve ser" uma expressão dos desejos e, se a realidade ainda não é isso, ela precisa ser abolida. "Os fatos não são valores. Portanto, os fatos devem ser superados" (ALVES, 1987, p. 93).

No entanto, a magia não tem o poder para fazer que as aspirações humanas se concretizem, já que, por detrás dela, encontra-se um homem impotente. A verdade da magia só será possível quando a impotência humana se transformar em poder.

Outro aspecto da imaginação é sua forma lúdica. Geralmente, associado às crianças, o lúdico também evidencia a primazia do desejo sobre a realidade. A sociedade atual tende a esquecer a atitude lúdica frente ao mundo. No processo de educação, isso fica bem evidenciado, uma vez que o mesmo acaba se transformando em uma imposição da realidade do mais forte sobre a realidade do mais fraco.

A educação pretende manter o sistema funcionando de acordo com as regras já impostas. Logo, a imaginação da criança deve ser controlada por aqueles que conhecem as regras do jogo social. Novamente, a questão envolve um ajustamento à realidade dada.

O comportamento da criança é caracterizado pelo brincar, e este não inclui intenção alguma de produzir um objeto, é mero fruto do prazer. O brinquedo é um fim em si mesmo, é uma proposta de alegria. Portanto, o prazer é o que rege a ação da criança. Ela é completamente dominada pelo "princípio de prazer". No entanto, quando ela amadurece, esse princípio é superado pelo "princípio de realidade". A criança assemelha-se ao neurótico, ela tem um comportamento não ajustado à realidade, pois ainda crê na onipotência 
do desejo. O brinquedo e a magia para Freud evidenciam um comportamento neurótico, uma vez que ambos não se ajustam à realidade.

No brinquedo, da mesma forma que na magia, o homem declara a prioridade axiológica do desejo. O brinquedo implica negação radical da lógica dominante, a qual evidencia um homem justificado por sua produção.

No entanto, a vida é um fim em si mesmo. A vida não deve ser pautada na produção. Essa crítica já está presente no pensamento de Marx. Dentro desse contexto, o brincar implica tanto uma crítica a uma sociedade que visa apenas à produção, quanto uma subversão dos valores impostos por essa sociedade.

As crianças entendem que, no brincar, o que está em jogo é o prazer. Como afirma Alves, "as crianças sabem muito bem disso: que o propósito único da vida é o prazer” (ALVES, 1990, p. 42). As construções feitas por elas não se transformam em ontologia. Elas têm ciência de que o mundo construído por elas pode ser desfeito a qualquer momento. Se a brincadeira não agrada mais, troca-se por outra, em que, novamente, a força motriz será o prazer. As crianças não estão comprometidas com a preservação da organização, mas sim com a preservação da vida.

Berger e Luckmann afirmam que a realidade é socialmente construída. $\mathrm{E}$, para que ela possa funcionar, é necessário que os homens assumam certos "papéis", os quais determinam a forma pela qual esse homem se relacionará com tal realidade construída. No entanto, eles asseveram que "os papéis podem ser reificados da mesma maneira que as instituições” (BERGER \& LUCKMANN, 1985, p. 125).

As crianças entendem que seus papéis em suas brincadeiras não estão reificados, mas se constituem como criações para propiciar prazer. Seus papéis nas brincadeiras não precisam se transformar em ontologia. Os adultos, no entanto, se esquecem disso e passam a agir como se a realidade do mundo fosse de tal forma que não pudesse ser mudada. O mundo então deixa de ser um lugar de prazer e passa a ser um lugar onde o que mais importa é a manutenção da ordem instituída. O papel do indivíduo é reificado, pois o adulto se converte naquilo que faz. O que era jogo se transforma em ontologia, se transforma em "verdade" e "realidade", e o homem, comprometido com essa visão, começa a forçar os outros a serem "realistas”, isto é, a se comportarem de acordo com as regras do jogo. E como tal jogo se transforma em verdade, ele tem que ser preservado, não pode ser negado. Instaura-se aí uma sociedade não mais fruto do prazer, mas da repressão. 
Pode-se notar que tanto no ato criador da cultura que visa estabelecer uma ordo amoris, quanto no jogo que visa produzir uma ordem que proporcione prazer, a mesma dinâmica está envolvida, a saber, a dinâmica de criar um mundo que seja expressão do desejo do homem.

No jogo se cria uma nova realidade a partir da imaginação, a partir da liberdade. Assim, da mesma forma que na magia, no jogo há uma supressão da realidade, que é declarada sem sentido. O jogo possui o mesmo caráter ético e profético da magia, pois nega que o mundo deve continuar sendo da forma que é. É um protesto contra a ordem estabelecida, suprimindo, portanto, a realidade, como na magia. Um novo mundo é construído, tendo em vista a busca de alegria. Há uma crença na onipotência da imaginação para criar um mundo que proporcione felicidade.

No entanto, falta às crianças o mesmo que falta à magia, ou seja, o poder. As crianças também são impotentes. A realidade se impõe de forma muito dura e o jogo passa então, da mesma maneira que a magia, a remeter a uma ausência. Os seus ideais só serão possíveis quando estiver presente o poder de transformar o mundo em uma ordo amoris.

O presente deve ser abolido por não permitir os atos criativos da imaginação. Tais atos trarão o futuro, apoiado sobre uma nova base, a saber, o desejo do homem.

\section{A dimensão utópica da imaginação}

Alves ressalta também a motivação utópica da imaginação. A utopia, segundo o autor, proclama que a organização social como forma de repressão e controle deve ser abolida, para que o planeta seja transformado no lugar da recuperação humana. Os sonhos de liberdade, de paz e de prazer, são negados ao homem pela sociedade que o reprime. Esta deve, portanto, ser abolida. Esse é o caminho utópico.

O olhar de Alves sobre a utopia é orientado para o futuro. Ele segue a sugestão de Manheim, em que a distinção entre utopia e resultado é feita de forma mais concisa.

Alves declara que "a utopia nasce quando a consciência toma os dados do presente, carrega-os com sua lembrança e com isso supera a dimensão única: O resultado é o futuro com uma fisionomia concreta: uma utopia" (ALVES, 1971, p. 22). A memória, como veremos a seguir, é um fator importante na geração das utopias e, por conseguinte, na constituição da imaginação. 
Alves, conforme Cervantes, afirma que a memória gera imaginação e, ao fazê-lo transforma o homem em um ser utópico. ${ }^{4}$ É na memória que se encontra a esperança de que o homem redescubra sua harmonia perdida com a natureza. A utopia, conforme já mencionado, se apoia na memória, pois no passado já se viveu em um mundo harmônico, de paz, de alegria e de prazer, e se tem a esperança de voltar a esse mundo. As utopias são sonhos sociais que se inspiram negativamente na realidade da qual emergem, constituindo uma forma de protesto e esperança ao mesmo tempo, visando transformar o mundo em que se vive em algo melhor.

Segundo Alves, a utopia é barrada pelo discurso científico. Tal discurso afirma que ela é u-topia (lugar nenhum) e que por isso deve ser abandonada. Mas o homem, que é um ser relacional, quer que o universo seja manifestação da sua intenção. Ele se nega a abandonar as utopias que expressam a sua esperança. Se o discurso da ciência assevera que essas utopias não podem ser realizadas, o homem não as abandona, mas tenta mudar a realidade. As utopias são então como os sonhos. Desse modo, como a magia e o jogo, não são feitos para predizer o futuro.

A imaginação não é, portanto, um instrumento de clarividência que revela o futuro, mas antes um espelho das condições vividas pelos homens em suas relações. A imaginação reflete o impossível que é vivido atualmente, o que faz que ela dependa das relações a partir das quais é gerada. Como já apontava Feuerbach em suas preleções, o homem é fruto do meio em que está inserido. O ser humano só fala daquilo que vive, e nada além disso. Só se vê o mundo mediado pela sociedade em que se encontra. ${ }^{5}$

As utopias não podem ser relatadas a partir da linguagem científica, pois as esperanças, os desejos estão para além do discurso da ciência. Como a linguagem só se expressa dentro de uma ordem vigente, tudo aquilo que ultrapassa essa ordem não poderá ser dito por esse tipo de linguagem.

As utopias, portanto, não são sonhos neuróticos, como queria Freud, mas revelam a dinâmica vivida pelos homens. Manheim aponta que a inteligibilidade das utopias consiste na situação estrutural do estrato social que, em um dado tempo, as espose. "A substância e a forma da utopia não ocorrem em um campo independente da vida social” (MANHEIM, 1976, p. 230, 231).

\footnotetext{
4 Sobre esse ponto, cf. Alves, Rubem, Some thoughts on a program for ethics, 1971, p. 166,167.

5 Cf. Feuerbach, Ludwig, Preleções sobre a essência da religião, 1989, p. 140, 141.
} 
Dessa forma, pode-se dizer que a utopia é algo natural ao ser humano, assim como os sonhos. E da mesma forma que estes, aquela revela os desejos ocultos do coração do homem. O último, ao se ver sufocado pela presente realidade, começa a suspeitar que ela deve ser abolida. Nesse momento, nasce a utopia. A imaginação conduz o homem a uma nova terra, onde as regras do jogo da realidade são substituídas por regras humanas. O coração começa a nomear as coisas ausentes. O futuro se abre não mais como continuação do presente, mas como uma tarefa possível, como algo que pode ser criado de acordo com as intenções do coração. Aqui se abre o caminho para a liberdade, o homem agora age por amor a um futuro que não existe em lugar algum (u-topia).

Alves afirma que é preciso "engravidar o presente", o que significa que o futuro tem que aparecer no presente. Não é um agir "para que" algo aconteça, mas agir "como se" esse algo já estivesse presente. A dinâmica do "Reino de Deus" é revelada.

A visão utópica liberta o homem do determinismo das forças materiais, e com isso ele se percebe livre para criar um mundo que é a expressão do seu amor. Essa visão demonstra que o homem não perdeu sua esperança, ele ainda quer criar um futuro que lhe seja amigo, que lhe cause alegria. Vê-se então a lógica da criatividade em seu limite. Há uma derrubada dos pressupostos antigos que impediam o homem de viver uma vida humana. O princípio de realidade é dominado pelo princípio de prazer. A alegria e o prazer tomam conta do mundo, pois o ser humano aniquilou a ordem que o aprisionava e se reconciliou com a realidade, não com aquela que o reprimia, mas com uma nova, fundada no desejo. E isso ele fez dando poder à esperança para que realizasse o "ato mágico".

Segundo Alves, "o oculto segredo da visão utópica diz que o homem não terá descanso e permanecerá infeliz até o dia em que as suas esperanças triunfem sobre os fatos. (...), Eu tenho esperança implica em eu desejo. E eu desejo consiste sempre no desejo de poder" (ALVES, 1987, p. 122).

\section{Considerações finais}

Alves aponta que a utopia é sempre definida pelo grupo dominante como utopia, pois ele determina o que pode ser considerado possível e o que é considerado impossível. "A possibilidade e a impossibilidade são relativas às estruturas que as fundamentam" (ALVES, 1987, p. 124). 
Para Alves, portanto, as utopias são manifestações da imaginação do homem. Elas demonstram que o homem ainda acredita que a ordem vigente pode e deve ser abolida, e em nome dessa esperança ele começa a agir de forma a gerar o futuro como extensão de seu próprio corpo. Um lugar de prazer, de alegria, onde não haja nem sofrimento, nem dor. E é sob essa mesma perspectiva que a religião é vista no pensamento alvesiano. Por ser fruto da imaginação, ela é capaz de subverter a ordem vigente e estabelecer o reino de Deus na terra.

\section{Referências}

ALVES, Rubem. Some thoughts on a program for ethics. Union Seminary Quarterly review, v. 26, n. 2, p. 166-167, 1971. In: CERVANTES-ORTIZ, Leopoldo. A teologia de Rubem Alves: poesia, brincadeira, erotismo. Campinas: Papirus, 2005, 250 p.

A Gestação do futuro, 2. ed. Campinas: Papirus, 1987, 199 p.

Hijos del mañana: imaginación, creatividad y renacimento cultural. Tradução do inglês por Juan José Coy. Salamanca: Sígueme, 1976. Título original: Tomorrow's child: imagination, creativity and the rebirth of culture.

_. O suspiro dos oprimidos, 6. ed. São Paulo: Paulus, 2006, 180 p.

_. Tempus fugit, 6. ed. São Paulo: Paulus, 1990, 108 p.

BERGER, Peter Ludwig; LUCKMANN, Thomas. A construção social da realidade: tratado de sociologia do conhecimento, 7. ed. Petrópolis: Vozes, 1985, 247 p.

FEUERBACH, Ludwig. A essência do cristianismo, 2. ed. Lisboa: Fundação Calouste Gulbenkian, 2002, 454 p.

FREUD, Sigmund. Formulações sobre os dois princípios do funcionamento mental. Rio de Janeiro: IMAGO, 1976, 406 p. (Obras Psicológicas Completas de Sigmund Freud; 12).

O mal estar da civilização. Rio de Janeiro: IMAGO, 1976, 309 p. (Obras Psicológicas Completas de Sigmund Freud; 21).

FROMM, Erich. Conceito marxista de homem, 3. ed. Rio de Janeiro: Zahar Editores, 1964,233 p.

MALINOWSKI, Bronislaw. Magic, science or religion, 1948, p. 79. In: ALVES, Rubem. A Gestação do futuro, 2. ed. Campinas: Papirus, 1987, 199 p.

Submetido em: 29-03-2017

Aceito em: 18-7-2017 